\title{
The environmental and socially engaged palaeontologist - suggestions for action at conferences and beyond
}

\author{
Marcelo R. Sánchez-Villagra, Gabriel Aguirre-Fernández, \\ Anusuya Chinsamy-Turan, and Catherine Badgley
}

\begin{abstract}
The several refugee crises, the continuous degradation of the environment, and the nativism of some influential religious and political sectors are bringing about a new era of activism in some sectors of society. Given the deep-time perspective, the international nature of palaeontology, the exposure through field work and museum visits to intercultural exchanges in different geographic settings, and the importance of the preservation and care of collections, the 'social fabric' that surrounds palaeontologists is appropriate for engaging the sensibility and awareness that current times demand. In fact, many colleagues often refer to these major issues and express informed opinions through social media. Concrete and immediate actions are urgently needed. But in an age of information over-load, sorting through ways in which to act that are environmentally and socially responsible can be a challenge. Our aim here is to provide a set of suggestions that concern the organization of scientific meetings; in many cases, these actions also apply to other concrete activities in the professional life of the palaeontologist and to practitioners of other disciplines as well. We are aware that there is no final word on how to reduce the environmental impact of our work-related routines and it is hard to generalize suggestions for all stages of academic life and countries of the world. We offer suggestions not as experts but as concerned scientists and global citizens.
\end{abstract}

Marcelo R. Sánchez-Villagra. Universität Zürich, Paläontologisches Institut und Museum, Karl-SchmidStrasse 4, 8006 Zürich, Switzerland. m.sanchez@pim.uzh.ch

Gabriel Aguirre-Fernández. Universität Zürich, Paläontologisches Institut und Museum, Karl-SchmidStrasse 4, 8006 Zürich, Switzerland. gabriel.aguirre@pim.uzh.ch

Anusuya Chinsamy-Turan. University of Cape Town, Biological Sciences, Private Bag X3, Rhodes Gift, 7701, South Africa. anusuya.chinsamy-turan@uct.ac.za

Catherine Badgley. University of Michigan, Ann Arbor, Michigan 48109, USA. cbadgley@umich.edu

Keywords: sustainability; climate change; extinction

Submission: 17 February 2017 Acceptance: 31 August 2017

Copyright: September 2017 Society of Vertebrate Paleontology. This is an open access article distributed under the terms of the Creative Commons Attribution License, which permits unrestricted use, distribution, and reproduction in any medium, provided the original author and source are credited.

creativecommons.org/licenses/by/4.0/

Sánchez-Villagra, Marcelo R., Aguirre-Fernández, Gabriel, Chinsamy-Turan, Anusuya, and Badgley, Catherine, 2017. The environmental and socially engaged palaeontologist - suggestions for action at conferences and beyond. Palaeontologia Electronica 20.3.4E: 1-7. https://doi.org/10.26879/172E

palaeo-electronica.org/content/2017/1994-commentary-environmentally-engaged 
'Earth is such a pretty blue and pink and white pearl in the pictures NASA sent me ... It looks so clean. You can't see all the hungry, angry earthlings down there - and the smoke and the sewage and trash and sophisticated weaponry ...'

Kurt Vonnegut, 1969, New York Times Magazine

\section{INTRODUCTION}

The several refugee crises, the continuous degradation of the environment, and the nativism of some influential religious and political sectors are bringing about a new era of activism in some sectors of society. Given the deep-time perspective, the international nature of palaeontology, the exposure through field work and museum visits to intercultural exchanges in different geographic settings, and the importance of the preservation and care of collections, the 'social fabric' that surrounds palaeontologists is appropriate for engaging the sensibility and awareness that current times demand (Sánchez-Villagra and MacLeod, 2014). In fact, many colleagues often refer to these major issues and express informed opinions through social media. Concrete and immediate actions are urgently needed. But in an age of information over-load, sorting through ways in which to act that are environmentally and socially responsible can be a challenge. Our aim here is to provide a set of suggestions that concern the organization of scientific meetings; in many cases, these actions also apply to other concrete activities in the professional life of the palaeontologist and to practitioners of other disciplines as well. We are aware that there is no final word on how to reduce the environmental impact of our work-related routines and it is hard to generalize suggestions for all stages of academic life and countries of the world. We offer suggestions not as experts but as concerned scientists and global citizens.

There is increasing evidence that human activities are altering the Earth system to levels that threaten its resilience (Barnosky, 2014; Steffen et al., 2015). The deep-time perspective informs us that perturbations of a geological or astronomical nature can set in motion changes that would belittle even the huge impacts that humans are having on the environment (MacLeod, 2015). However, this does not diminish the negative effects of resource exploitation and rampant consumerism on human well-being (Kasser and Kanner, 2003), on human cultures (Klein, 1999, 2014), and on marine and terrestrial ecosystems (Spicer, 2006).

Many of the measures that we suggest here address the criticisms voiced in Dauvergne's (2016) book 'Environmentalism of the Rich'. Dauvergne argued that many actions are ineffective as in the end, they justify consumerism, and the ecological movement from the industrialized nations "saps the energy and outrage that drive protest, and encourages complacency." (Humes, 2016). Perhaps some of the measures we suggest fit in this scheme (e.g., consume local resources), but we do suggest measures that would significantly change the ways that we function today in our professional meetings.

Scientific meetings can serve as catalysts of knowledge production through intellectual communication and exchange, professional socializing and networking, and the legitimization of new subfields or paradigms (Gross and Fleming, 2011). Every year, over 80 million people around the world attend a meeting or conference (UNEP, 2009). Given the number of scientific associations and scholarly societies (more than 17500 according to Kirchner, 2004), there may not be a single day-apart from major holidays, perhaps -in which a conference is not being held somewhere in the world (Gross and Fleming, 2011). Most researchers attend conferences as a part of their practice. Participation in conferences, especially as a contributor, is integral to the life of an academic (Jacobs and McFarlane, 2005). With this in mind, the United Nations Environment Programme (UNEP) published the Green Meeting Guide (UNEP, 2009) to 
be used both internally and externally as a reference when organizing meetings of up to 200 participants. Following its success, the Sustainable Events Guide (UNEP, 2012) focused on larger events and incorporated feedback from the first version. The list developed below is largely inspired by the criteria outlined in the Sustainable Events Guide (UNEP, 2012), with many aspects modified according to our personal experiences at scientific conferences. Through this list we note five specific measures that could reduce conference-related environmental and social burdens. The UNEP guide and several links provided below contain checklists with some of the recommendations listed here and many more, all useful resources for conference organizers.

\section{FIVE MEASURES TO MAKE SCIENTIFIC MEETINGS MORE ENVIRONMENTALLY AND SOCIALLY SUSTAINABLE}

\section{Reduce Traveling}

Travel accounts for a significant part of the environmental impact of a conference. Reducing travel would reduce not only greenhouse gas emissions, but also potential waste related to the journey (e.g., tickets, food in plastic bags, bottled water). Obviously, eliminating traveling altogether is not an option, as no traveling means no conference. Here we suggest how to optimize and prioritize resources:

1. Make international meetings bi-annual, with regional meetings for the in-between years. Should a conference be held annually, it should not be compulsory that all its officers attend every year (or they can participate via video-conference).

2. Combine conferences: Coordination among societies could optimize conference travel timing, so that they follow each other or are held concurrently. This also has the advantage of exposing scientists to a more diverse circle of people and ideas.

3. Reduce pre-conference travel: Decide whether it is necessary for all members of the organizing committee to meet in person. Perhaps a videoconference can replace travel for matters that cannot be discussed via email.

4. Promote virtual participation: Virtual presence (remote presence using a video conference platform) is the most sustainable and least disruptive form of participation since no travel is involved. Virtual presence can be a form of participation in oral presentations or committee meetings. A speaker may wish to give a talk from her/his home institution to be streamed live or previously-recorded. Likewise, talks given at a conference can be live-streamed or recorded to be made available to people who cannot or prefer not to travel. An example of this practice is at www.palaeocast.com, which offers live-streaming coverage and recorded talks for large-scale (e.g., SVP) and medium-scale (e.g., Progressive Palaeontology and EAVP) conferences (see Erratum). Many of those recorded conference talks are accessible online on the website platform. The "question and answer" time can be live-streamed even for prerecorded talks.

\section{Reduce Waste}

Here we suggest feasible measures to reduce the generation of waste and to reuse, recycle, or repurpose unavoidable waste:

1. Do not give out pre-charged conference bags, t-shirts, USB-sticks, or the like. Deduction of the costs of these items from the conference fee will be good for everyone, especially for those from less-privileged parts of the world. Conference organisers should also actively promote the reduction of free giveaway by sponsors.

2. Avoid distributing bottled water. Publicize when tap water is drinkable, or if need be, provide water dispensers, and recyclable cups.

3. Badges should be reusable or at least recyclable. One option would be to print the name badges in textile 'paper' that sticks well on fabric and other surfaces, and these can be reused at other meetings. The ideal would be if participants attended a conference previously, they would already have a name tag that is usable. 
4. Ban the use of plastics and styrofoam. Often a serviette (napkin) is all that is needed for snacks; otherwise provide biodegradable crockery and cutlery.

5. Provide less processed food during breaks: local fruit from organic sources is not only more environmentally sound but also healthier. If it costs more than the usual biscuits, order less, and that may reduce waste.

6. Ensure that recycle and compost bins are available throughout the conference venue.

\section{Consume Resources and Use Modes of Local Transportation That Are Environmentally and Socially Sound}

We recommend looking for measures that foster economic, social, and environmental benefits for the local community; therefore, all purchasing decisions to acquire goods and services should take into account the environmental and social impacts.

1. Engage local colleagues and include them on the conference organizing committee. Do not leave all decisions to a conference administration company. Local colleagues could provide a list of providers (restaurants, cafes) that are environmentally friendly or socially engaged. This information would be transmitted to the participants via social media, in conference information, and at the opening ceremony, with the disclaimer that organisers do not have a vested interest in any of those businesses.

2. Food should be in season, locally produced, and environmentally responsible. All coffee served should be fair trade, and single use sugar/sweetener packets should be avoided. As a general rule, it costs less energy to produce fruits and vegetables than products of animal origin, and we suggest preference should be made for the former.

3. Avoid products containing palm oil, since palm-oil plantations are a major cause of tropical deforestation.

4. If serving fish, ensure that only Marine Stewardship Council (MSC) certified (https:// www.msc.org/) or some other similar environmentally sustainable guideline is used for purchasing fish.

5. For eating out, recommend only restaurants and cafes that are socially engaged or environmentally friendly.

6. Conference banquets should offer high-quality vegetarian meals as the standard, with an option for meat-eaters (i.e., the reverse of the way menus are offered these days). Furthermore, engaging local caterers or conference organizers that employ disadvantaged groups (e.g., disabled people, refugees) would have the effect of not only contributing to the local area in a concrete way, but also serve as an example to those attending, who could emulate this in their own institutions.

7. Use more ecologically sustainable transportation. The information in the conference website should encourage participants to consider train journeys over car/coach or airplane journeys, and car/coach journeys over airplane. As an example, for a trip from Zurich to Paris ( 1,000 km return journey), the carbon footprint produced by airplane travel or alone in a car is about the same $\left(290 \mathrm{~kg} \mathrm{CO}_{2}\right.$; amount estimated using the 'myclimate' calculator; with airplane $\mathrm{CO}_{2}$ emissions being $0.291 \mathrm{t}$ and those of a medium-sized [ $8 \mathrm{~L} / 100 \mathrm{~km}$ ] car using petrol fuel being $0.286 \mathrm{t}$ ), while travelling by train produces 10 times less $\mathrm{CO}_{2}$ (Warland et al., 2016).

8. Use environmentally friendly venues. Host the conference in an energy-efficient building, or in a university building which would then be supported, as opposed to conference facilities in a chain hotel. When available at the city hosting a conference, this should take place at a LEED building (www.usgbc.org/leed) - or at a venue meeting some criteria of sustainability. At the very least, conferences should be held at venues that can be accessible by public transportation.

\section{Be Outspoken on the Topic of Environmental and Social Sustainability, Honour and Celebrate Achievements in the Ecological and Social Impacts of the Field}

1. When making suggestions for changes in the way conferences are organized, make it clear that you are seeking to reduce the negative effects on the environment and society. Ask for feedback once the conference is over and provide information incorporating participant feedback to future conference organizers. 
2. Create special awards that recognize achievements in promoting awareness about the environment and social justice. It is also worth considering the social and ecological achievements of scientists when giving awards. Recommend people who have been good mentors and have provided socially constructive actions as recipients of prizes, awards, and recognition, not just scientists who are successful in terms of publications and other scholarly achievement.

3. Provide incentives to researchers who choose to spend their sabbaticals in developing countries, and perhaps raise funds to encourage such actions.

4. Evaluate the social and ecological impacts of fieldwork on local communities, and ensure that researchers are aware of these from the outset.

\section{Compensate for the Carbon Footprint}

In order to compensate for those aspects of a conference that cannot be changed, it is possible to support organisations that address offsetting carbon footprints by creating projects that are ecologically and socially sound. Green groups dedicated to offsetting have been criticized, as this activity has been used by some multinational corporations to protect their freedom to pollute the atmosphere. In fact, many examples of organisations producing 'carbon credits' are fraudulent, and are instead actively destructive to local ways of life (Klein, 2014). For these reasons, organisations to be supported should be carefully scrutinized. Following the principle that effective environmentalism is one that reduces use of resources, this measure is to be considered as the last resort.

A positive case in point is the non-profit organization 'myclimate' that provides software that calculates the carbon footprint of a conference (https:// co2.myclimate.org/en/event_calculators/new). The conference organizers provide data related to infrastructure, mobility, energy, food, accommodation, etc., and 'myclimate' calculates the conference's carbon footprint. A conference may use a 'climate-neutral label' if the carbon footprint emissions are compensated by paying an amount that would be used in climate protection projects that seek to reduce the emission of greenhouse gases. Alternatively, the conference website may ask the 'myclimate' developers or a similar organization to design a travel $\mathrm{CO}_{2}$-emissions calculator that can be available for delegates to compensate their own carbon footprints during the payment process.

\section{CONCLUSIONS}

Scientific conferences often mirror the norms and 'culture' of an organization, and ensuring that a conference is environmentally friendly could have a multiplicative effect for those attending. The coordinated support of social justice and environmental protection consists of community activities and social interactions, which have the added benefit of giving satisfaction and psychological well-being (Botton, 2012).

The paradigm in which academic palaeontology operates is that of 'growth first and foremost', a model currently questioned by diverse political and economic organisations (e.g., http://www.ecomodernism.org/manifesto-english/). Cultural changes in the way conferences are organized do not mean shrinkage of the discipline, but rather a change in the way in which things are done.

Participation in conferences is clearly an important aspect of professional life; however, excessive conference participation can result in costly consumption and diminishing professional rewards (Gladwell, 2013; Figure 1). The expression 'small is beautiful' conveys the virtues of modesty, appropriate scale, and sustainable livelihoods (Schumacher, 1973). This maxim could be the basis of a new philosophy of success and achievement that prioritizes and considers the costs of 'big' and endless 'growth'. In this regard, it would be important to modify the measures of success of a meeting or a society: these should not be an ever-increasing number of attendees, the 
same way that the h-index or some other similar index cannot serve alone to evaluate scientific performance.

The implementation of ecologically and socially conscious measures in organizing conferences does not need additional bureaucracy, but through the simple ethos of reduction and prioritizing can reach its goals.

Many organisations offer concrete advice about how conferences and organisations can incorporate more sustainable practices. Below are links to a few sites that provide further suggestions or elaborate on the points raised above.

A Canadian foundation, the David Suzuki Foundation, offers specific advice on a variety of matters concerning reducing one's impact on the environment:

http://www.davidsuzuki.org/what-you-can-do/queen-of-green/faqs/waste/how-to-hosta-green-conference/.

Socialbrite, an organization concerned with assisting non-profits and organizations with all facets of social media, provides specific advice on being green and elaborates further on some of the points raised in this article:

http://www.socialbrite.org/2011/10/04/how-to-host-a-sustainable-conference/.

An organization based in Washington, D.C., USA, 'Leadership in Energy and Environmental Design' (LEED), provides standards for the development of green buildings:

http://ch.usgbc.org/leed.

The Environmental Association for Universities and Colleges (EAUC) is an organization coordinating sustainability efforts of universities and colleges, private-sector and commercial organisations, mostly in the UK:

http://www.eauc.org.uk/.

Travel calculators are useful to estimate travel emissions and compare between air, car, or train journey. An example includes: https://www.myclimate.org/. The Tyndall Travel Tracker is specifically designed for academics and weights the value of a journey based on career stage:

http://www.futureearth.org/blog/2016-jan-19/tyndall-travel-tracker-cumulativelychanging-our-travel-behavior-one-flight-time.

What we have presented here is not prescriptive, and we do not claim to know what is best for everyone. Rather, we hope that the guidelines we have outlined above will enable our palaeontological associations and organisations to embrace and increase sustainable, environmentally friendly practices in upcoming conferences. We further hope that this article inspires awareness about how important it is to implement sustainable practices that show our commitment to protect environments and social well-being. 


\section{ACKNOWLEDGEMENTS}

MRS-V thanks L. Meier and H. Götzmann for inspiration, and M. Cvitkusic for comments on an earlier version of the manuscript. We thank N. Stevens and an anonymous reviewer for constructive reviews.

\section{REFERENCES}

Barnosky, A. 2014. Dodging Extinction: Power, Food, Money, and the Future of Life on Earth. University of California Press, Berkeley.

Dauvergne, P. 2016. Environmentalism of the Rich. MIT Press, Cambridge.

de Botton, A. 2012. Religion for Atheists: A NonBeliever's Guide to the Uses of Religion. Penguin, London.

Gladwell, M. 2013. David and Goliath: Underdogs, Misfits, and the Art of Battling Giants. Little, Brown and Company, New York.

Gross, N. and Fleming, C. 2011. Academic conferences and the making of philosophical knowledge. Social Knowledge in the Making, 151-179.

Humes, E. 2016. Sustainability: Laying waste. Nature, 538:458. doi:10.1038/538458a

Jacobs, N. and McFarlane, A. 2005. Conferences as learning communities: Some early lessons in using 'back-channel' technologies at an academic conference - distributed intelligence or divided attention? Journal of Computer Assisted Learning, 21:317-329. doi:10.1111/j.1365-2729.2005.00142.x

Kasser, T. and Kanner, A.D. 2003. Psychology and Consumer Culture: The Struggle for a Good Life in a Materialistic World. American Psychological Association, Washington.

Kirchner, F. 2004. World Guide to Scientific Associations and Learned Societies. KG Saur, München.

Klein, N. 1999. No Logo: Taking Aim at the Brand Bullies. Knopf, Canada.

Klein, N. 2014. This Changes Everything. Capitalism vs the Climate. Simon Schuster, New York.

MacLeod, N. 2015. The Great Extinctions: What Causes Them and How They Shape Life. Firefly Books, Ontario.
Sánchez-Villagra, M.R. and MacLeod, N. 2014. Issues in Palaeobiology: A Global View. Scidinge Hall Verlag, Zürich.

Schumacher, E.F. 1973. Small Is Beautiful: Economics as If People Mattered. Harper reprint edition (2010), New York.

Spicer, J.I. 2006. Biodiversity: A Beginner's Guide. Oneworld Books, Oxford.

Steffen, W., Richardson, K., Rockström, J., Cornell, S.E., Fetzer, I., Bennett, E.M., Biggs, R., Carpenter, S.R., de Vries, W., de Wit, C.A., Folke, C., Gerten, D., Heinke, J., Mace, G.M., Persson, L.M., Ramanathan, V., Reyers, B., and Sörlin, S. 2015. Planetary boundaries: Guiding human development on a changing planet. Science, 347:1259855. doi:10.1126/science. 1259855

United Nations Environment Programme. 2009. Green Meeting Guide.

http://www.iclei-europe.org/fileadmin/templates/icleieurope/files/content/Topics/Sustainable_Events/ GreenMeetingGuide.pdf

United Nations Environment Programme. 2012. Sustainable Events Guide. http://www.iclei-europe.org/fileadmin/templates/icleieurope/files/content/ICLEI_IS/Topics_pages/ Sustainable_Events_Guide_May_30_2012_FINAL.p df

Vonnegut Jr, K. 1969. "Excelsior! We are going to the Moon! Excelsior!" New York Times Magazine, July 13, 1969, SM10.

Warland, L., Hilty, L., Küng, J., and Reinhard, J. 2016. Factsheet business travel. Sustainability Team, University of Zurich.

http://www.sustainability.uzh.ch/dam/jcr:91789646-

f8a1-4b57-8e25-d27de47902b4/2016-08-

17_Factsheet_Business\%20Travel.pdf 


\section{ERRATUM}

After publications the authors were made aware that SVP meeting policy specifically prohibits the photography and recording of presentations at our annual meetings without the express permission of the author.

Original text:

Likewise, talks given at a conference can be live-streamed or recorded to be made available to people who cannot or prefer not to travel. An example of this practice is at www.palaeocast.com, which offers live-streaming coverage and recorded talks for large-scale (e.g., SVP) and mediumscale (e.g., Progressive Palaeontology and EAVP) conferences.

Replacement text:

Likewise, talks given at a conference can be live-streamed or recorded to be made available to people who cannot or prefer not to travel. An example of this practice is at www.palaeocast.com, which offers live-streaming coverage and recorded talks of conferences such as PalAss, SVPCA and EAVP.

6 February 2018 